\title{
Cognitive Function in Patients With Chronic Granulomatous Disease: A Preliminary Report
}

\author{
Maryland Pao, M.D., Edythe A. Wiggs, Ph.D. \\ Melissa M. Anastacio, B.A., Jenny Hyun, B.A. \\ Ellen S. DeCARlo, R.N., Judi T. Miller, R.N. \\ Victoria L. Anderson, C.R.N.P., HARry L. Malech, M.D. \\ John I. Gallin, M.D., Steven M. Holland, M.D.
}

\begin{abstract}
Chronic granulomatous disease is an inherited immunodeficiency in which phagocytes fail to generate superoxide and its metabolites, resulting in severe recurrent infections and frequent hospitalizations. Chronic illness and frequent hospitalizations can affect growth and development as well as social and educational opportunities. Since no data have been reported on cognitive functioning in patients with this illness, the authors sought to examine cognitive function in a group of patients with chronic granulomatous disease. A retrospective chart review of 26 patients seen and followed at the National Institutes of Health who had received cognitive testing at the request of parent or staff was performed. Demographic information including medical, psychiatric, and developmental histories was gathered. Six patients (23\%) were found to have an IQ of 70 or below, indicative of cognitive deficits, and all of those patients had defects in the membrane-linked cytochrome b558. The prevalence of cognitive deficits in this selected population of chronic granulomatous disease patients was high. The determination of the true distribution of cognitive functioning in the general chronic granulomatous disease population is important, since cognitive deficits have implications for educational planning and potential therapies such as transplantation and gene therapy in children.

(Psychosomatics 2004; 45:230-234)
\end{abstract}

$\mathrm{C}$ hronic granulomatous disease is a genetic immunodeficiency in which phagocytes fail to generate an oxidative burst because of mutations in the genes of the reduced nicotinamide adenine dinucleotide phosphate (NADPH) oxidase complex. Patients with this disorder have recurrent life-threatening infections with catalase-

Received Aug. 8, 2002; revision received July 30, 2003; accepted Aug. 28, 2003. From the Department of Psychiatry, Children's National Medical Center, Washington, D.C.; and the Laboratory of Host Defenses, National Institute of Allergy and Infectious Diseases. Address reprint requests to Dr. Holland, the Laboratory of Host Defenses, National Institute of Allergy and Infectious Diseases, National Institutes of Health, Building 10, Room 11N103, 10 Center Dr., MSC 1886, Bethesda, MD 208921886; smh@nih.gov (e-mail).

Copyright (C) 2004 The Academy of Psychosomatic Medicine. positive bacteria and fungi. Exuberant tissue granuloma formation can obstruct the bladder, kidney, esophagus, and pylorus. Granulomatous colitis is seen in up to $30 \%$ of chronic granulomatous disease patients. ${ }^{1}$

Chronic granulomatous disease affects about 1 in 200,000 individuals and usually appears in early childhood, but more adult cases are being recognized. ${ }^{2}$ In chronic granulomatous disease, four separate and distinct molecular genetic defects are known and characterized. Glycoprotein (gp) $91^{\text {phox }}$ (phagocyte oxidase) is located at $\mathrm{Xp} 23.1$; the other three (p22 $2^{\text {phox }}, \mathrm{p} 47^{p h o x}$, and $\mathrm{p} 67^{\text {phox }}$ ) are autosomal recessive and found on chromosomes 16, 7, and 1, respectively. In the United States, approximately $70 \%$ of chronic granulomatous disease cases are $\mathrm{X}$-linked, about 
$25 \%$ are due to homozygous mutations in $\mathrm{p} 47^{\text {phox }}$, and the remainder are split between $\mathrm{p} 22^{\text {phox }}$ and $\mathrm{p} 67^{\text {phox }}{ }^{2}$.

In the past, children with chronic granulomatous disease suffered severe and often fatal infections of the lung, liver, lymph nodes, bone, or skin, with death in the second or third decade being common. However, antibacterial, antifungal, and cytokine treatments for chronic granulomatous disease have improved dramatically over the last decade, and substantial numbers of patients now live into adulthood. Therefore, issues involving the social, academic, and cognitive function of these patients have taken on increased importance. Cognitive and behavioral abnormalities have been identified in a variety of immunodeficiencies, including Chédiak-Higashi syndrome, ${ }^{3}$ Griscelli syndrome,${ }^{4}$ leukocyte adhesion deficiency type II, ${ }^{5}$ glucose-6-phosphate dehydrogenase deficiency, ${ }^{6}$ and adenosine deaminase deficient severe combined immunodeficiency $^{7}$ (Table 1). However, cognitive functioning has not been investigated in patients with chronic granulomatous disease. Chronic illness can negatively impact a child's normal physical and psychosocial development as well as limit social and educational opportunities. Cognitive deficits may further complicate chronic illness. When these deficits are as severe as mental retardation, treatment in many realms-medical, educational, and social-is affected.

An observation made by one of us (M.P.) that an unusually large number of chronic granulomatous disease patients referred for evaluation had IQ scores that were $\leq 70$ prompted a careful retrospective chart review to determine the frequency of cognitive deficits in this previously unstudied group.
Mental retardation is defined as "significant subaverage general intellectual functioning existing concurrently with deficits in adaptive behavior and manifested during the developmental period," with an IQ two standard deviations below the mean (i.e., 70 or below; mean $\mathrm{IQ}=100$ ). ${ }^{8}$ In addition to low IQ, the diagnosis of mental retardation requires significant limitations in adaptive functioning in at least two of the following areas: self care, communication, home living, social skills, community use, self direction, health and safety, functional academics, leisure, and work, as typically assessed with the Vineland Adaptive Behavior Scales. The "developmental period" refers to the first 18 years of life. ${ }^{9}$

While the prevalence of mild mental retardation is between $1 \%-3 \%$ of the population, its etiologies are myriad. ${ }^{8}$ Chromosomal abnormalities, inborn errors of metabolism, and genetic syndromes are seen in almost $20 \%$ of cases of mild mental retardation and almost $50 \%$ of cases of severe mental retardation. ${ }^{10}$

The early identification of cognitive deficits facilitates appropriate guidance of children, adolescents, and their families to a variety of specialized resources, including enhanced school settings, speech and language therapies, and planning for socialization, home living, functional independence, and employment.

\section{METHOD}

A retrospective chart review was conducted of 26 chronic granulomatous disease patients followed at the National Institutes of Health who underwent neuropsychological

\begin{tabular}{|c|c|c|}
\hline Syndrome & Gene Product & MIM $^{\mathrm{a}}$ \\
\hline Chédiak Higashi syndrome & LYST & 2145000 \\
\hline Immunodeficiency-centromeric instability facial anomalies syndrome & DNA methyltransferase 3B & 242860 \\
\hline Nijmegen breakage syndrome & Nibrin/p95 & 251260 \\
\hline $\begin{array}{l}\text { Immunodeficiency with cleft lip/palate, cataract, hypopigmentation, } \\
\text { and absent corpus callosum }\end{array}$ & Unknown & 242840 \\
\hline Ataxia telangiectasia & Ataxia telangiectasia, mutated & 208900 \\
\hline Griscelli syndrome & Myosin VA & 214450 \\
\hline Dyskeratosis congenital (including Hoyerall-Hreidarsson syndrome) & DKC1 & 305000 \\
\hline Cowden disease & CD Phosphatase, tensin homolog & 158350 \\
\hline Glucose-6-phosphate dehydrogenase deficiency & G6PD & 305900 \\
\hline $\begin{array}{l}\text { Leukocyte adhesion deficiency type II [congenital disorder of } \\
\text { glycosylation (CDG) IIc] }\end{array}$ & GDP fucose transporter-1 & 266265 \\
\hline Velocardiofacial syndrome & DGCR & 192430 \\
\hline Adenosine deaminase deficiency & ADA & 102700 \\
\hline
\end{tabular}

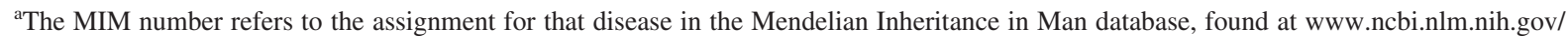
omim/. 
testing for educational or behavioral issues at the request of family or staff. Patients ranged in age from 5 to 27 years and spoke English.

For each patient we collected demographic, medical, and genotypic data as well as documented available developmental, medical, radiologic, family, and psychiatric histories. Medical histories included previous or ongoing receipt of interferon gamma, a cytokine used to prevent infection in chronic granulomatous disease, and information from brain imaging with CT or MRI scanning, which were performed as medically indicated.

A licensed clinical psychologist (E.A.W.) administered one of three versions of the Wechsler intelligence tests, depending on the age of the patient. ${ }^{11-13}$ Some patients were also given one or more of the following: Vineland Adaptive Behavior Scales: Interview Edition, Wide Range Achievement Test-Third Edition (WRAT-III), McCarthy Scales of Children's Abilities, and WoodcockJohnson Psycho-Educational Battery. One patient was examined elsewhere.

The distribution of IQ in the chronic granulomatous disease patients was compared with the normal distribution as reported by Batshaw. ${ }^{10} \mathrm{~A}$ one-tailed exact binomial test was performed to determine the true value of low IQ in our chronic granulomatous disease patient group. Differences in IQ by genotype were analyzed by a two-tailed $\mathrm{t}$ test.

\section{RESULTS}

Twenty-six chronic granulomatous disease cases were reviewed, $88 \%(\mathrm{~N}=23)$ of whom were male. The mean age at time of cognitive testing was 12.9 years, the median age was 10 years. Sixty-nine percent $(\mathrm{N}=18)$ were Caucasian, $19 \%(\mathrm{~N}=5)$ were African American, and $12 \%(\mathrm{~N}=3)$ were Hispanic. Seventy-seven percent $(\mathrm{N}=20)$ had the gp91 ${ }^{\text {phox }}$ (X-linked) chronic granulomatous disease genotype, while the $\mathrm{p} 47^{\text {phox }}, \mathrm{p} 22^{\text {phox }}$, and $\mathrm{p} 67^{\text {phox }}$ genotypes were seen in $15 \%(\mathrm{~N}=4), 4 \%(\mathrm{~N}=1)$, and $4 \%(\mathrm{~N}=1)$, respectively. This distribution is typical for the disorder: $70 \%$ of cases are due to the X-linked form of the disease, and are therefore male; the remaining $30 \%$ of cases are autosomal recessive and have an equal sex ratio. Therefore, approximately $85 \%$ of all cases are male. The numbers of African American and Hispanic subjects in our patient group are approximately the same as in the general United States population.

Thirteen patients had brain imaging data. Findings included a brain abscess $(\mathrm{N}=1, \mathrm{IQ}=70)$, calcifications
$(\mathrm{N}=1, \mathrm{IQ}=87)$, hydrocephalus $(\mathrm{N}=1, \mathrm{IQ}=44)$, leukomalacia $(\mathrm{N}=1, \mathrm{IQ}=86)$, and cortical atrophy $(\mathrm{N}=1$, $\mathrm{IQ}=75$ ). Eight patients had normal CT or MRI results (IQs of 88 [N=2], 100,104, 105, 113, 124, and 126). Twentyfour patients (92\%) had been receiving interferon gamma at some point in their lives, but only 16 patients $(62 \%)$ were receiving interferon gamma at the time of IQ testing.

The mean IQ among the tested chronic granulomatous disease patients was 89 (Figure 1). A 1-tailed exact binomial test shows that the rate of low IQ was higher in this selected chronic granulomatous disease patient group than in the general population $(\mathrm{p}=0.0001)$. Out of the 26 evaluated patients, six (23\%) had an IQ $\leq 70$. All of the patients with IQ $\leq 70$ had defects associated with the membranelinked cytochrome b558 (gp91 ${ }^{\text {phox }}$ or $\mathrm{p} 22^{\text {phox }}$ ). Of these six, five were male with the $\mathrm{X}$-linked chronic granulomatous disease genotype, and one was female with the p22 $2^{\text {phox }}$ genotype. There was no statistical difference between IQ levels by genotype ( $\mathrm{gp} 91^{\text {phox }}$ and $\mathrm{p} 22^{\text {phox }}$ : IQ range $=44-124$; $\mathrm{p} 47^{\text {phox }}$ or $\mathrm{p} 67^{\text {phox }}$ : IQ range $\left.=75-126\right)(\mathrm{p}=0.36)$, but the number of patients with cytosolic factor defects was small.

\section{DISCUSSION}

The current study was based on a selected group of referred patients with an inborn error affecting the generation of superoxide, a molecule critical to innate and acquired immunity. We cannot distinguish whether the cognitive deficits seen here are distinctly related to chronic granuloma-

FIGURE 1. Distribution of IQ Determinations in 26 Patients With Chronic Granulomatous Disease $^{\mathrm{a}}$

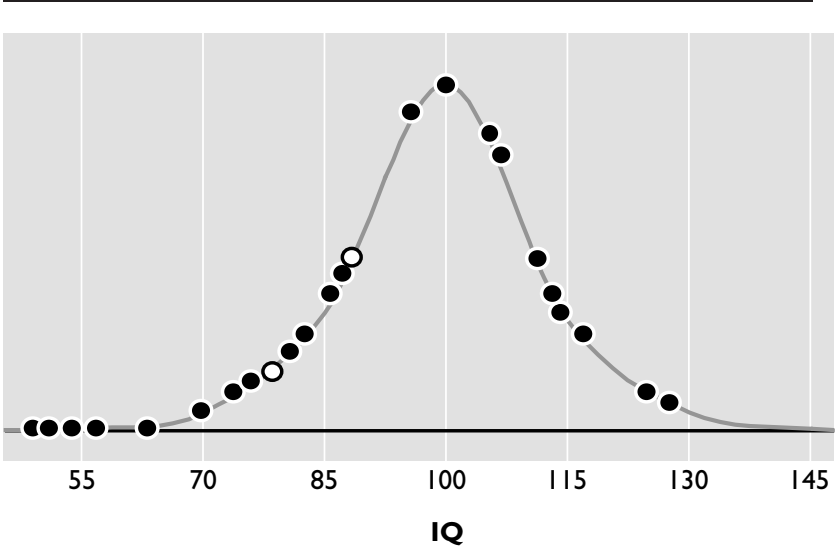

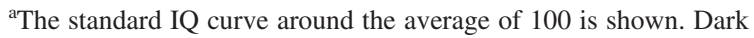
filled circles indicate one patient each, light filled circles (at 75 and 88) indicate two patients each. Note the preponderance of data points on the left side of the curve. 
tous disease or to other variables, such as occult or overt central nervous system infection, severity of illness, multiple and prolonged hospitalizations, high rates of school absenteeism, or decline in family socioeconomic status. However, studies in other similar chronic illnesses have not shown cognitive deficits. For instance, patients with cystic fibrosis are also susceptible to serious and frequent infections, have multiple long-term hospitalizations, receive multiple courses of similar intravenous antibiotics, and have multiple episodes of fever and respiratory compromise. However, previous studies have shown average to above average IQ in cystic fibrosis patients, suggesting that chronic illness is not per se a cause of cognitive impairment. ${ }^{14,15}$

The lack of superoxide production in chronic granulomatous disease could lead to a variety of effects that could critically influence the development of the brain and cognition, either directly or through failed interaction with other pathways leading to abnormal development of neurons, microglia, or oligodendrocytes. In addition to their critical roles in host defense, reactive oxidants are crucial signaling molecules 1) in the activation of nuclear factor kappa B (NFkB); ${ }^{16}$ 2) in the processing of antigens for surface display by adherent cells, which may influence the course of CNS immune responses; ${ }^{17} 3$ ) in T cell responses to antigen, through a nitric oxide mediated pathway; ${ }^{18}$ and 4 ) in the promotion of cellular apoptosis, which may affect neurons, glia, or infiltrating inflammatory cells. ${ }^{19}$

NADPH oxidase activity is present in mouse microglia and neurons. ${ }^{20,21}$ Absence of NADPH-dependent superoxide production as found in the chronic granulomatous disease mouse model leads to attenuated brain ischemic damage due to both hematopoietic and brain parenchymal contributions. ${ }^{22}$ Excess scavenging of superoxide by overexpressed superoxide dismutase genes in transgenic mice leads to impaired long-term potentiation, a crucial step in the generation of memory. ${ }^{23}$ Since lack of superoxide is the fundamental defect in patients with chronic granulomatous disease, and this is the effect that would be reproduced in the presence of an overabundance of superoxide dismutase, impaired generation of memory should be investigated in these patients. Therefore, the generation and presence of superoxide may have effects well beyond those of bacterial killing alone.

A $23 \%$ prevalence rate of cognitive deficits in this selected chronic granulomatous disease population is significantly higher than the 1\%-3\% low IQ prevalence in the general population. Cognitive and behavioral abnormalities have been recognized in adenosine deaminase deficient severe combined immunodeficiency by Rogers et al. ${ }^{7}$ The direct relationship they showed between plasma adenosine deaminase levels and IQ suggests that the severity of the immunodeficiency is linked to cognitive ability. This might be due to excess adenosine or mediated through the immune defect. Of special interest in view of future therapies for chronic granulomatous disease is that successful bone marrow transplantation did not alter behavioral problems in adenosine deaminase deficient severe combined immunodeficiency, suggesting that there may be early irreversible brain damage. A significant number of immunodeficiencies affecting both the innate and acquired immune systems have been associated with cognitive defects, as shown in Table 1.

Out of the 156 patients with chronic granulomatous disease we have seen at NIH, we examined only the charts of 26 patients who received cognitive testing, and those that were examined had been referred for testing for cause, undoubtedly biasing our sample. Despite this admitted bias, the data presented here are compelling. Recently, Winkelstein et al. ${ }^{2}$ reported 368 patients with chronic granulomatous disease compiled through a national registry. The six cases of IQ $\leq 70$ reported here would be the number expected in the total nationally identified patient population with chronic granulomatous disease, if the rate of IQ $\leq 70$ were at the normal level of $1 \%-3 \%$. These low rates of cognitive function as measured by IQ may actually reflect a more discrete defect or set of defects, such as those that might affect learning or memory.

The rate of cognitive deficits was surprisingly high in this selected chronic granulomatous disease population. At this point, it is not clear whether this reflects sequelae of recurrent infections or of the defect in superoxide generation. Regardless of the etiology of these problems, their rate in this cohort was high. As treatments improve and substantial numbers of patients with chronic granulomatous disease live into adulthood, it is critical to know whether there are chronic granulomatous disease-specific cognitive and behavioral phenotypes. Early identification of cognitive deficits and behavioral difficulties allows children, adolescents, and their families to seek a variety of specialized resources. These unanticipated findings in chronic granulomatous disease patients deserve further prospective study in humans as well as in available mouse models.

The authors thank Timothy Heeren, Ph.D., Associate Professor of Biostatistics, Boston University School of Public Health, for his assistance. 


\section{Cognition in Chronic Granulomatous Disease}

\section{References}

1. Segal BH, Leto TL, Gallin JI, Malech HL, Holland SM: Genetics, biochemistry, and clinical features of chronic granulomatous disease. Medicine (Baltimore), 2000; 79:170-200

2. Winkelstein JA, Marino MC, Johnson RB Jr, Boyle J, Curnutte J, Gallin JI, Malech HL, Holland SM, Ochs H, Quie P, Buckley RH, Foster CB, Chanock SJ, Dickler H: Chronic granulomatous disease: report on a national registry of 368 patients. Medicine (Baltimore) 2000; 79:155-169

3. Blume RS, Wolff SM: The Chédiak-Higashi syndrome: studies in four patients and a review of the literature. Medicine (Baltimore) 1972; 51:247

4. Hurvitz H, Gillis R, Klaus S, Klar A, Gross-Kieselstein F, Okon E: A kindred with Griscelli disease: spectrum of neurological involvement. Eur J Pediatr 1993; 152:402-405

5. Etzioni A, Frydman M, Pollack S, Avidor I, Phillips ML, Paulson JC, Gershoni-Baruch R: Brief report: Recurrent severe infections caused by a novel leukocyte adhesion deficiency. N Engl J Med 1992; 327:1789-1792

6. Dowd B: Glucose-6-phosphate dehydrogenase and its relationship to mental retardation. Med Hypotheses 1980; 6:7-11

7. Rogers MH, Lwin R, Fairbanks L, Gerritsen B, Gaspar HB: Cognitive and behavioral abnormalities in adenosine deaminase deficient severe combined immunodeficiency. J Pediatr 2001; 139:4450

8. Palmer FB, Capute AJ: Mental retardation. Pediatrics in Review 1994; 15:473-479

9. American Psychiatric Association: Diagnostic and Statistical Manual of Mental Disorders, 4th ed (text revision). Washington, DC, American Psychiatric Association, 2000

10. Batshaw ML: Mental retardation in the child with developmental disabilities. Pediatr Clin North Am 1993; 40:507-521

11. Wechsler D: Wechsler Adult Intelligence Scale-Third Edition (WAIS-III). San Antonio, The Psychological Corporation, 1981

12. Wechsler D: Wechsler Preschool and Primary Scale of Intelligence-Revised (WPPSI-R). San Antonio, The Psychological Corporation, 1989

13. Wechsler D: Wechsler Intelligence Scale for Children-Third Edition (WISC-III). San Antonio, The Psychological Corporation, 1991
14. Thompson RJ, Gustafson KE, Meghdadpour S, Harrell ES, Johndrow DA, Spock A: The role of biomedical and psychosocial processes in the intellectual and academic functioning of children and adolescents with cystic fibrosis. J Clin Psychol 1992; 48:3-10

15. Stewart S, Campbell RA, Kennard B, Nici J, Silver CH, Waller DA, Uauy R: Neuropsychological correlates of cystic fibrosis in patients 5-8 years old. Children's Health Care 1995; 24:159-173

16. Kono H, Rusyn I, Bradford BU, Yin M, Dikalova A, Kadiiska MB, Connor HD, Mason RP, Segal BH, Holland SM, Thurman $\mathrm{RG}$ : Identification of the source of oxidants in alcoholic liver disease: studies in knockout mice. J Clin Invest 2000; 106:867-872

17. Heijnen CJ, van der Meer JW, Zegers BJ: Altered antigen processing in the induction of the in-vitro antigen-specific $\mathrm{T}$ helper cell function in patients with chronic granulomatous disease. Clin Exp Immunol 1986; 66:111-117

18. Van der Veen RC, Dietlin TA, Hofman FM, Pen L, Segal BH, Holland SM: Superoxide prevents nitric oxide suppression of lymphocyte proliferation: decreased autoimmune encephalomyelitis in NADPH oxidase knockout mice. J Immunol 2000; 164:51775183

19. Kasahara Y, Iwai K, Yachie A, Ohta K, Konno A, Seki H, Miyawaki T, Taniguchi N: Involvement of reactive oxygen intermediates in spontaneous and CD95 (Fas/APO-1)-mediated apoptosis of neutrophils. Blood 1997; 89:1748-1753

20. Lavigne MC, Malech HL, Holland SM, Leto TL: Genetic requirement of $\mathrm{p} 47$ phox for superoxide production by murine microglia. FASEB J 2001; 15:285-287

21. Tammariello TP, Quinn MT, Estus S: NADPH oxidase contributes directly to oxidative stress and apoptosis in nerve growth factordeprived sympathetic neurons. J Neurosci 2000; 20:RC53(1-5)

22. Walder CE, Green SP, Darbonne WC, Mathias J, Rae J, Dinauer MC, Curnutte JT, Thomas GR: Ischemic stroke injury is reduced in mice lacking a functional NADPH oxidase. Stroke 1997; 28:2252-2258

23. Thiels E, Urban NN, Gonzalez-Burgos GR, Kanterewicz BI, Barrionuevo G, Chu CT, Oury TD, Klann E: Impairment of longterm potentiation and associative memory in mice that overexpress extracellular superoxide dismutase. J Neurosci 2000; 20: 7631-7639 